\title{
A Review of Combined Regenerative Suspension and Electromagnetic Braking system
}

\author{
Prof. Gaffar G. Momin ${ }^{1} \mid$ Rushikesh Barve ${ }^{1} \mid$ Manasi Shah ${ }^{1} \mid$ Nikita Sutar ${ }^{1} \mid$ Dominic Jibin James ${ }^{1}$ \\ ${ }^{1}$ Mechanical Department, Pimpri-Chinchwad College of Engineering, Pune, Maharashtra, India
}

\section{To Cite this Article}

Prof. Gaffar G. Momin, Rushikesh Barve, Manasi Shah, Nikita Sutar and Dominic Jibin James, "A Review of Combined Regenerative Suspension and Electromagnetic Braking system", International Journal for Modern Trends in Science and Technology, 6(9): 18-23, 2020.

\section{Article Info}

Received on 06-August-2020, Revised on 20-August-2020, Accepted on 25-August-2020, Published on 29-August-2020.

\section{ABSTRACT}

Considering the rate of depletion of the available oil-based fuels, Renewable Energy Technologies are receiving significant attention in these years. It is, therefore, necessary to find alternatives to energy sources. This project focusses on one such alternative. A study is done on a vehicle suspension system and braking system. Suspension in vehicles produces linear vibrations due to the roughness on the roads. These vibrations are absorbed the shock absorbers and dissipated in the form of heat. In the case of a conventional braking system, a huge amount of heat is lost due to friction. This study proposes a design of a system where the heat lost in the suspension system is extracted, converted into a usable form of electrical energy and stored in batteries. This stored energy is further used in the operation of electromagnet powered brakes. Using the Regenerative Suspension System reduces the waste of energy in the shock absorbers and gives an alternative energy source and use of the Electromagnetic Braking System ensures frictionless braking. Thus, the overall consumption of energy is reduced by a notable amount.

KEYWORDS: Regenerative Suspension, Electromagnetic Braking, Energy Harvesting, Green Energy

\section{INTRODUCTION}

As the depletion of oil resources and increasing greenhouse effects, methods to avoid wasting resources and reduce $\mathrm{CO}^{2}$ emissions are attracting significant attention. The transportation sector is that the second-largest source of $\mathrm{CO}^{2}$ emissions, which are primarily produced by gasoline, diesel, heavy oils, and jet fuel, consuming approximately $27 \%$ of total world main energy [1]. Consequently, reducing energy consumption, fully utilizing energy, and recovering P.E. within the transportation sector is of great significance [2]. Electric vehicles (EVs) have gained increasing popularity thanks to lower energy consumption and reduced pollution. The adoption of EVs around the world can effectively alleviate the issues above
[3]. But thanks to battery size and capacity restrictions, EVs have limited range. This discourages people from shifting towards this greener transportation approach.

This problem is often tackled by successfully saving and harvesting the energy which is wasted within the form ofheat in shock absorbers and traditional brakes. Solutions like regenerative suspension and electromagnetic braking are in development since the 1990s. But thanks to recent technological advances and emergence of economic Electric Vehicles, development of those systems is in limelight. Segel et al. [4] analyzed the energy dissipation of dampers of a passenger vehicle and shown that the entire power of 4 dampers was about 200W when running on a poor road at the 
speed of $13.4 \mathrm{~m} / \mathrm{s}$. These data indicate that the energy dissipation of auto suspension can't be ignored. Also, it's found that electromagnetic brakes can develop a negative power which represents nearly twice the utmost power output of a typical engine, and a minimum of 3 times the braking power of an exhaust brake. These performances of electromagnetic brakes make them a far more competitive candidate for alternative retardation equipment compared with other retarders.

\section{ELECTROMAGNETIC BRAKING SYSTEM}

The commonly used types of brakes in automobiles are drum and disc brakes. Various types of braking system used are hydraulic, pneumatic etc. The basic principle involved in any conventional braking system involves the conversion of energy from kinetic to thermal. Hence, these conventional braking systems have certain disadvantages like friction between the components which result in loss of energy, energy lost in the form of heat etc.

The new revolutionary technology of the electromagnetic brakes is nowadays used to eliminate these losses. The electromagnetic braking system is a braking system used in the light motor \& heavy motor vehicles like car, jeep, truck, busses etc. This system is a combination of electro-mechanical concepts [5]. This system slows down the object through a force created by electromagnetic induction which acts as a resistance to the motion of the vehicle. This system aims to minimize brake failure to avoid road accidents. It also reduces the maintenance of the braking system. An advantage of this system is that it maybe used on any vehicle with minor modifications to the transmission and electrical systems.

Types of Braking Systems and Types of Brakes:

1. Hydraulic braking system

2. Electromagnetic braking system

3. Servo braking system

4. Mechanical Braking System

Types of Brakes:

1. Disk Brakes

2. Drum Brakes

\section{i. Working Principle:}

"If a bit of copper wire was wound, round the nail then connected to A battery, it will create an electromagnet. The magnetic flux that's generated within the wire, from this current, is known by using the "right-hand thumb rule". The strength of the magnetic flux may be changed by changing both wire size and also the amount of wire (turns)." This principle of working is employed within the mentioned prototype model.

The fields of Electromagnetic brakes can be made to operate at almost any DC voltage and the torque produced by the brake will be the same as long as the correct operating voltage and current are employed with the correct brake. A constant current power supply is right for accurate and maximum torque from a brake. If a non-regulated power supply is employed the magnetic flux will degrade because the resistance of the coil goes up. Basically, the hotter the coil gets the lower the torque will be produced by about a mean of $8 \%$ for each $20^{\circ} \mathrm{C}$.

Based on $\mathrm{V}=\mathrm{I} \times \mathrm{R}$,

as resistance increases available current falls.

An increase in resistance often results from rising temperature because the coil heats up, according to:

$\mathrm{Rf}=\mathrm{Ri} \times[1+\mathrm{aCu} \times(\mathrm{Tf}-\mathrm{Ti})]$

\begin{tabular}{|ll|}
\hline \multicolumn{2}{|l|}{ Nomenclature } \\
$\mathrm{Rf}$ & final resistance \\
$\mathrm{Ri}$ & initial resistance \\
$\mathrm{aCu}$ & copper temperature coefficient of \\
resistance & \\
$\mathrm{Tf}$ & final temperature \\
$\mathrm{Ti}$ & initial temperature \\
\hline
\end{tabular}

If the temperature is fairly constant, and there's an issue of enough service factor in the design for minor temperature fluctuation, by slightly oversizing the brake can compensate for degradation. This will allow the utilization of a rectified power supply, which is more cost-effective than a constant current supply.

ii. Construction and Working:

Components of the model: 
- Disc brake plate

- Disc liner

- Braking coil

- Tension spring

- Battery (minimum 12 volts)

- Alloy wheel

- Electro-magnet

ii.

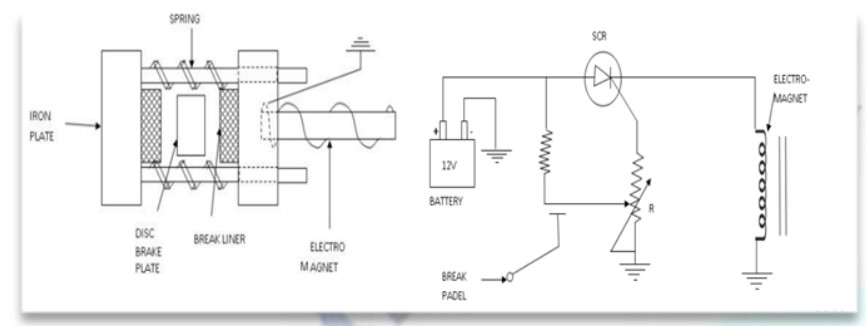

Fig 2.1

The electromagnetic braking system is found to be more reliable as compared to other braking systems. Even a small leakage in a mechanical oil or air braking system may lead to complete failure of brakes but in the electromagnetic braking system as four-disc plates, coils and firing circuits are attached individually on each wheel, even if anyone coil fails, the brake does not completely fail as the remaining three coil works properly. Also, this system needs very little maintenance. This innovative braking system does not only help in effective braking but also helps in avoiding the accidents as well as in reducing the frequency of accidents to a minimum.

\section{REGENERATIVE SUSPENSION SYSTEM}

Energy harvesting has been a more popular topic recently with ever-increasing environmental pollution [6]. The primary function of a conventional suspension system is to minimize vibration irregularities on roads. These shock absorbers emit vibration energy in form of heat [7]. Regenerative shock absorbers are a type of suspensions that convert motion due to vibration into useful electrical energy instead of dissipating it in the form of heat. This recovered energy can be stored in batteries for future use. In a non-electric automobile, losses in energy due to uneven roadways largely affect fuel efficiency. Hence, a regenerative suspension system can help in increasing fuel economy.

\section{i.Types of Regenerative Suspension Systems}

Types of regenerative suspension systems are categorized into their construction and ways of energy generation. There are two types based on construction viz Linear designs, Bidirectional rotary designs and Unidirectional rotary designs [7]. Examples based on paths of energy generation are piezoelectric, hydraulic, pneumatic, electromagnetic, hybrid (Hydraulic + Electromagnetic), etc.

\section{Certain demerits of hydraulic suspension:}

1) Less efficient due to high-pressure requirements.

2) Toxic fluids are used in these systems, and so rifts and rupture may cause pollution.

Advantages of Electromagnetic Suspension system are:

1) Increase inefficiency.

2)Improvement in dynamics and stability.

3)Accurate force control. [8]

\section{Construction:}

A linear electromagnetic regenerative suspension considered here mainly consists of stator coil windings and permanent magnet array. The basic construction of the system is given in [Fig 3.1]

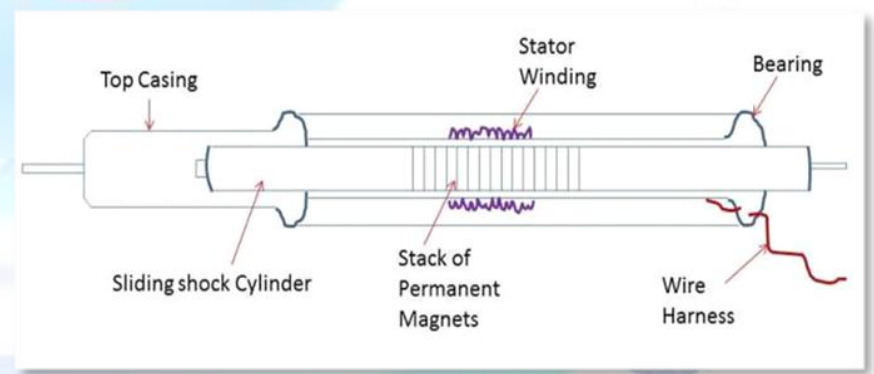

Fig 3.1

\section{COMBINED REGENERATIVE SUSPENSION AND ELECTROMAGNETIC BRAKING SYSTEM}

A setup incorporating both these systems will be designed which will enable us to test the functionality and compatibility of both the systems. The proposed structure of the setup is shown by using the block diagram shown in [Fig 3.1]. The given system will consist of four modules: Road input module, Regenerative damper module, Energy storage module, Electro-magnetic Braking module. As the road input module is triggered, it will simulate normal bump condition and give the input to the tyre. The damper module will then react to this input and absorb the shock while 
generating energy. The energy generated by the damper will be stored in the energy storage module using supercapacitors and batteries. The braking module will then covert this electric energy into magnetic energy which will be used to apply the brakes.

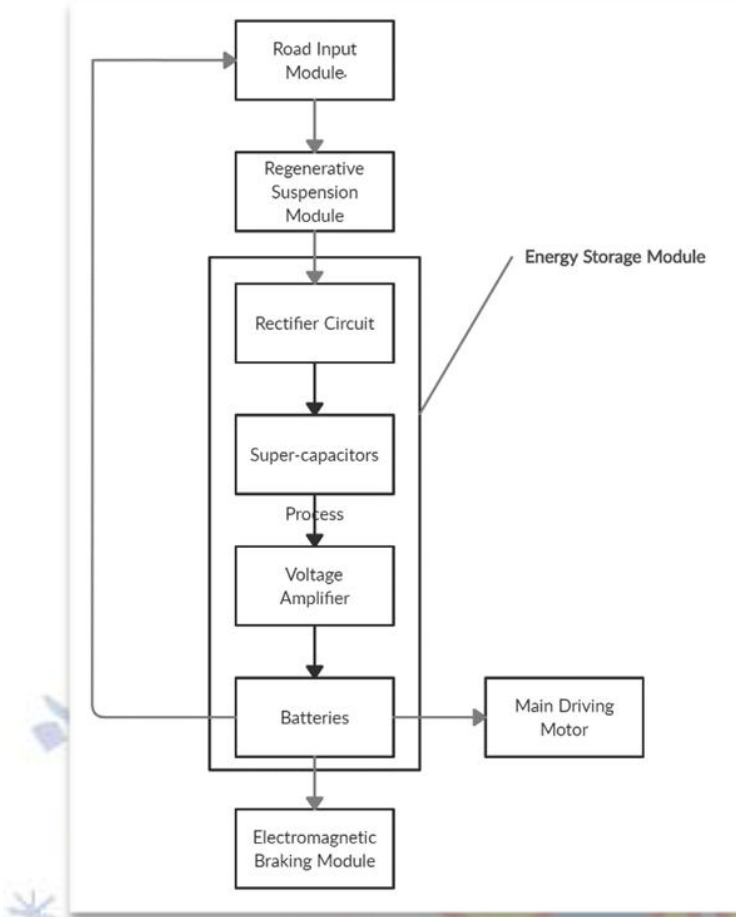

Fig 4.1

\section{i. Road input module}

The tyre will be placed on a wooden surface below which there will be a DC motor operated disc cam which will generate the required bump. Analysis of this setup should be done on different road surfaces. By using cams of different radii and by varying the speed of the DC motor, different bump heights and bump interval will be achievable. The classification shown in [Fig 3.2] can be referred.

\begin{tabular}{|c|c|c|c|c|}
\hline $\begin{array}{c}\text { Class } \\
\text { number (cn) }\end{array}$ & $\begin{array}{c}\text { Road } \\
\text { Class }\end{array}$ & $\begin{array}{c}S d_{(n=1)}{ }^{A} \\
\left(\times 10^{-6} \mathrm{~m}^{3}\right)\end{array}$ & $\begin{array}{c}S_{R M S(n=1)}{ }^{\mathrm{B}} \\
\left(\times 10^{-3} \mathrm{~m}\right)\end{array}$ & $\begin{array}{c}S_{R M S(n=1)} \\
(\mathrm{mm})\end{array}$ \\
\hline 1 & $\mathrm{~A}$ & 0.16 & 0.4 & 0.4 \\
\hline 2 & $\mathrm{~B}$ & 0.64 & 0.8 & 0.8 \\
\hline 3 & $\mathrm{C}$ & 2.56 & 1.6 & 1.6 \\
\hline 4 & $\mathrm{D}$ & 10.24 & 3.2 & 3.2 \\
\hline 5 & $\mathrm{E}$ & 40.96 & 6.4 & 6.4 \\
\hline 6 & $\mathrm{~F}$ & 163.84 & 12.8 & 12.8 \\
\hline 7 & $\mathrm{G}$ & 655.36 & 25.6 & 25.6 \\
\hline 8 & $\mathrm{H}$ & 2621.44 & 51.2 & 51.2 \\
\hline
\end{tabular}

Fig 4.2

\section{ii. Regenerative Damper module}

There are three parts in electromagnetic suspension namely vibration input, transmission and generator module [9]. The electromagnetic induction principle used here states that if there exists relative motion between stator winding and permanent magnets will develop a voltage across the ends of the conductor in a magnetic field. The suspension input module transfers the vibration/kinetic energy to transmission. This mechanism converts linear vibrations into the unidirectional motion of the generator shaft [9]. Rotation of the generator shaft depends on the frequency of vibration due to irregularities. The generator module converts this energy into useful electric energy.

\section{iii. Energy storage module}

As the electrical energy generated by the damper will be discontinuous and irregular, a rectifier circut will be used. This rectified output then will be given to a set of supercapacitors. Whenever the stored energy will exceed a certain threshold value, it will be discharged into a lead-acid battery. To get the desired discharging rate, various experiments are carried out. Thus, the threshold value is found. A voltage regulator will be used between the supercapacitors and the battery to ensure proper voltage regulation. The voltage will be amped by using voltage amplifiers and then rectified. The circuit is shown [Fig 4.3]

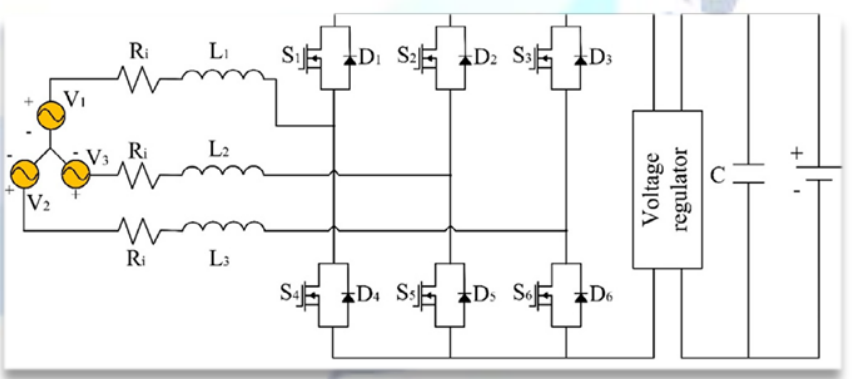

Fig 4.3

\section{iv. Electromagnetic Braking Module}

In the electro-magnetic braking system, the electro-magnetic property is used due to which action of braking is be done. This module consists of Electro-magnets, iron plate, liners, tension spring, disc brake plate. The brake liners are attached with electro-magnet and iron plate individually and both plates insert the disc plate and this plate is fixed with wheels. The battery of a 
minimum of 12 volts is used for external power supply. Silicon control rectifier (SCR) is used in the system. The gate pulse of SCR is fired and the output of SCR is given to electro-magnet for applying brakes. This SCR provides high current to the electro-magnetic braking system and the electromagnet attracts the iron plate towards itself. This method opposes the motion of wheels.

\section{v. CONCLUSION}

Conventionally, the suspension and brakes are found to waste a lot of energy which can otherwise be converted for reuse. The vibration energy of vehicle suspension is dissipated as heat by the shock absorber, which wastes a considerable number of resources. The friction and heat produced in traditional (hydraulic, mechanical etc) braking are lost in absorption. Regenerative suspensions and alternative electromagnetic brakes bring hope for scavenging the wasted energy. All types of regenerative suspension and electromagnetic braking system are reviewed in this paper. A selective electromagnetic regenerative suspension system and a prototype model of EM brakes are also reviewed. A concept of combining these two systems is mentioned in this review paper. With the certain improvement of technology and improvisation in the concept, this combined system may become one of the promising trends in the vehicle industry.

\section{ACKNOWLEDGMENT}

Any accomplishment involves the efforts of many people. This review is no different. It is the combined effort of the team members and our guide that led us to this success.

Taking this opportunity to express our gratitude, we thank our guide Prof. Gaffar G. Momin whose support and encouragement helped us all the way. It was because of his patient guidance that this endeavour of ours could be materialized.

\section{REFERENCES}

[1] C. Fiori, K. Ahn, H.A. Rakha, Power-based electric vehicle energy consumption model: Model development and validation, Appl. Energy 68 (2016) 257-268

[2] X. Zhang, Z. Zhang, H. Pan , W. Salman , Y. Yuan, Y. Liu , A portable high-efficiency electromagnetic energy harvesting system using supercapacitors for renewable energy applications in railroads, Energy Convers. Manag. 118 (2016) 287-294
[3] R. Zhang, X. Wang, S. John, A comprehensive review of the techniques on regenerative shock absorber systems, Energies 11 (2018) 1167

[4] L. Lu , X. Han , J. Li , J. Hua , M. Ouyang, A review on the key issues for lithium-ion battery management in electric vehicles, J. Power Source 226 (3) (2013) 272-288

[5] Kumar, K.P., Kadoli, R., Kumar, M.V.A., Mechanical and magnetic analysis of magneto-strictive disc brake system, Industrial and Information Systems (ICIIS), 2010 International Conference, July 29 2010-Aug. 1 2010

[6] Design of the Hybrid Regenerative Shock Absorber and Energy Harvesting from Linear Movement, Mustafa Demetgul and Ismail Guney, Journal of Clean Energy Technologies, Vol. 5, No. 1, January 2017, https://www.researchgate.net/deref/http\%3A\%2F\%2 Fdx.doi.org\%2F10.18178\%2FJOCET.2017.5.1.349

[7] Regenerative Shock Absorber in the Vehicle Suspension System, Kireev A.V.1,a, Kozhemyaka N.M., Burdugov A.S. and Klimov A.V. Scientific and Technical Center "PRIVOD-N", Novocherkassk City, Krivoshlykova St., Rostov Region, Russian Federation. KAMAZ Innovation centre Ltd, Russian Federation, Moscow.

https://www.ripublication.com/ijaer17/ijaerv12n22_ 88.pdf

[8] Active Electromagnetic Suspension System for Improved Vehicle Dynamics Bart L. J. Gysen, Member, IEEE, Johannes J. H. Paulides, Member, IEEE, Jeroen L. G. Janssen, Member, IEEE, and Elena A. Lomonova, Fellow, IEEE. IEEE TRANSACTIONS ON VEHICULAR TECHNOLOGY, VOL. 59, NO. 3, MARCH 2010, https://www.researchgate.net/deref/http $\% 3 \mathrm{~A} \% 2 \mathrm{~F} \% 2$ Fdx.doi.org\%2F10.1109\%2FVPPC.2008.4677555

[9] Research Review of a Vehicle Energy-Regenerative Suspension System,XueyingLv 1,2, YanjuJi 1,2, Huanyu Zhao 1,2, Jiabao Zhang 1,2, Guanyu Zhang 1,2, Liu Zhang 1,2, College of Instrumentation \& Electrical Engineering, Jilin University, Changchun 130061, China; lvxy17@mails.jlu.edu.cn (X.L.); jiyj@jlu.edu.cn (Y.J.); zhaohyjlu@jlu.edu.cn (H.Z.); zhangjiabao@jlu.edu.cn (J.Z.), National Engineering Research Center of Geophysics Exploration Instruments, Jilin University, Changchun 130061, China https://doi.org/10.3390/en13020441. 